\title{
Desacralizando el espacio de lo narrable: (pos)memoria, autoficción y mercado editorial en Los topos y 76 de Félix Bruzzone
}

\section{Desacralizing the Space of the Narrateable: (Post)Memory, Autofiction and Publishing Market in Los topos and 76 by Félix Bruzzone}

\section{Resumen}

El objetivo de este artículo es presentar la novela Los topos y el libro de relatos 76 de Félix Bruzzone como los textos que inician un nuevo espacio narrativo público donde la generación de los hijos de los desaparecidos articulan su propia perspectiva sobre el trauma en Argentina. Propongo una lectura doble de ese nuevo espacio a partir de estos dos textos: primero, realizo un análisis de la reconfiguración del campo literario argentino después de 2001 y cómo el caso de Bruzzone, con un tránsito orgánicamente fluido entre circuitos editoriales independientes y transnacionales, abre el camino para otros autores con un posicionamiento estético e ideológico similar. Posteriormente, analizo en detalle cómo Bruzzone propone desacralizar el espacio de lo narrable sobre la (pos)memoria desde la parodia e incluso el diálogo con géneros como el policial y el fantástico, y el uso de la autoficción como mecanismo para subvertir los límites de la realidad y la ficción y negar la posibilidad de construir representaciones absolutas. Además, argumento que el objetivo de estas dos obras es crear una línea continua entre la represión y las desapariciones de la dictadura y la violencia del presente.

Palabras claves

mercado editorial; autoficción; parodia; posmemoria; violencia.

\begin{abstract}
The aim of this article is to present the novel Los topos and the book of short stories 76 by Félix Bruzzone as the texts that initiate a new public narrative space where the generation of the
\end{abstract}


children of the disappeared articulate their own perspective on trauma in Argentina. I propose a double reading of this new space from these two texts: first, I make an analysis of the reconfiguration of the Argentine literary field after 2001 and how the case of Bruzzone, with an organically fluid transit between independent and commercial publishers and local and international circuits, opens the way for other later authors with a similar aesthetic and ideological position; later, I analyze in detail how Bruzzone proposes to desacralize the space of the narrable through parody and even the dialogue with genres such as crime fiction and fantasy, and the use of autofiction as a mechanism to subvert the limits of reality and fiction and deny the possibility of constructing absolute representations. In addition, I argue that the objective of these two works is to create a continuous line between repression and the disappearances of the dictatorship and the violence in the present.

Keywords

Publishing Market; Autofiction; Parody; Postmemory; Violence.

A Juan Carlos Rodríguez (in memoriam) y Ana Gallego, por enseñarme a leer entrelíneas.

No hay mejor punto de arranque para el pensamiento que la risa. Y una conmoción del diafragma ofrece casi siempre mejores perspectivas al pensamiento que la conmoción del alma.

Walter Benjamin, Tentativas sobre Brecht

\section{El caso Bruzzone: carta abierta a la memoria y la tradición}

Con motivo del 40 aniversario del golpe de estado de Jorge Rafael Videla y el inicio de la última dictadura cívico-militar en Argentina (1976-1983), la revista argentina Anfibia editó un número especial en el que apareció publicada una carta que el narrador argentino Félix Bruzzone dirigía a sus padres (y también a sus hijos) y que tituló "Paciencia de tenedores y cucharas". En la carta, Bruzzone hace repaso de todos los obstáculos por los que ha pasado durante el complicado proceso de recabar información sobre las circunstancias que rodearon a las desapariciones de 
CATEDRAL TomAdA: Revista de crítica literaria latinoamericana / Journal of Latin American Literary Criticism Desacralizando el espacio de lo narrable: (pos)memoria, autoficción y mercado editorial en Los topos y 76 de Félix Bruzzone

su padre y su madre y la frustrante experiencia de seguir todo el juicio de la ESMA ${ }^{1}$ y hablar con sus verdugos. Esa carta constituye una declaración de intenciones que nos sirve para entender la importancia que Bruzzone le da al proceso mismo de escritura y cuáles son las claves sobre las que se sostiene su narrativa, y, de paso, también podemos inferir cómo proyecta su figura de autor en el campo literario argentino. Comienza así:

Queridos padres:

¿Cómo están? ¡Hace casi 40 años que no sé nada de ustedes! Cuando desaparecieron se dijo así, que estaban "desaparecidos”. ¡Pero eso ya lo sabíamos! Las soluciones tautológicas son buenas para hacer humor pavote, que es el que más me gusta. Pero sus desapariciones eran un caso más serio. [...] No se tomen todo esto demasiado en serio. Si de algo estoy cansado es de la lástima y de la seriedad. Son cosas serias, sí, y dan mucha pena, pero se pueden ver con cierta gracia. El buen humor aliviana siempre la espera.

En el contexto de la transición democrática en Argentina, la carta abierta a familiares desaparecidos se convirtió en un recurso habitual para conseguir colectivizar la gestión íntima del trauma y, de este modo, contribuir a la creación de un espacio desde el cual articular una memoria democrática pública. Sin embargo, aunque la carta de Bruzzone sigue teniendo el objetivo de lidiar desde el presente con el trauma y la ausencia-presencia fantasmagórica de los desaparecidos, la forma y el tono son radicalmente opuestos a otros ejemplos escritos por quienes vivieron el horror del genocidio siendo adultos ${ }^{2}$. Por tanto, la elección de este tipo de carta y el tono supone un gesto político que explicita la tensión entre el deseo de

${ }^{1}$ Escuela de Mecánica de la Armada, conocida por ser un campo de concentración, tortura y exterminio durante la dictadura.

${ }^{2}$ Un ejemplo de este tipo de manifestación pública son las cartas que el poeta Juan Gelman escribió a su hijo desaparecido y a su nieta, a quien ni siquiera conocía cuando hizo pública la carta. 
dialogar e inscribirse en la tradición literaria y cultural argentina, y, al mismo tiempo, la necesidad de situarse fuera o incluso crear una ruptura frontal con ella.

Como bien señala Beatriz Sarlo, la literatura que surge en los años inmediatos al final de la última dictadura militar tenía aún una voz demasiado constreñida por el miedo institucionalizado y esto habría impedido el surgimiento de registros "distintos a la evocación subjetiva, el non fiction, la alegoría o el realismo" ("Condición”). Por tanto, será la generación 1.5, la de los hijos de los desaparecidos, la que reclamará el derecho a cuestionar el relato de la generación anterior, a investigar sin miedo el pasado y a proponer innovaciones discursivas que articulen nuevas formas de identidad personal y colectiva. En su artículo “Comienzos de la novísima narrativa argentina (2001-2011)", Ana Gallego Cuiñas aborda un grupo de primeras novelas de escritores jóvenes argentinos entre las que se encuentra Los topos (2008) de Félix Bruzzone y señala que todas tienen en común una marcada necesidad generacional de "evidenciar con más nitidez la posición del escritor con respecto a su tradición nacional" (4). Siguiendo este argumento, propongo una lectura de la novela de Bruzzone Los topos y su contraparte en forma de libro de relatos, 76 (2008), como los textos literarios paradigmáticos que inauguran la búsqueda de un espacio generacional propio que, aunque no rompe totalmente los lazos que lo unen a la tradición literaria argentina y a la generación anterior debido a una cierta continuidad en los temas, sí propone otro lenguaje desde el que articular nuevas modalidades para hablar sobre el trauma y la condición de hijos o familiares de desaparecidos. Como se puede observar en la carta "Paciencia de tenedores y cucharas", Bruzzone condensa ahí algunos estilemas y topos recurrentes que vertebrarán todo su proyecto narrativo: un discurso autoficcional (que intentará superar e impugnar) cargado de humor negro y combinado con elementos que intentan romper con cualquier posibilidad de elaborar un relato realista, mimético y referencial (como la parodia, lo onírico y lo psiconalítico o el diálogo con la novela negra o el fantástico). La elección de estos recursos narrativos y retóricos tiene el claro objetivo de transgredir y desacralizar tanto los discursos institucionalizados de la militancia alrededor de organizaciones 
CATEDRAL TomADA: Revista de crítica literaria latinoamericana / Journal of Latin American Literary Criticism Desacralizando el espacio de lo narrable: (pos)memoria, autoficción y mercado editorial en Los topos y 76 de Félix Bruzzone

pro derechos humanos, como el rígido y estrecho marco narrativo de las principales representaciones asociadas al imaginario de las víctimas de la dictadura que habían sido creadas y custodiadas por la "generación militante" (Drucaroff).

Sin embargo, además de lo anterior, creo que hay dos aspectos que son realmente innovadores y que diferencian el caso de Bruzzone de otros coetaneos: primero, la construcción de una arqueología de la violencia y las desapariciones que no se detiene en la represión de la dictadura, sino que llega hasta el presente ${ }^{3}$; y, segundo, su relación con el mercado editorial caracterizada por el tránsito fluido entre circuitos independientes locales y comerciales transnacionales. Por tanto, antes de analizar los elementos discursivos concretos de Los topos y 76, abordaré el contexto ideológico y socioeconómico en el que nace la obra de Bruzzone con el objetivo de entender más cabalmente cómo fue el proceso de consolidación del nuevo paradigma en cuanto a la manera de producir, circular y leer literatura en la Argentina actual y, en particular, cómo contribuyó Bruzzone a ese cambio.

\section{De mediadores independientes a la literatura mundial: Bruzzone y la poética de la resistencia}

La ruptura generacional que se puede apreciar en la narrativa de Bruzzone no parte únicamente de diferencias discursivas, sino, además, del drástico cambio en las propias condiciones materiales y económicas del campo literario argentino debido a la crisis financiera de 2001. Muchos de los escritores que iniciaron su andadura literaria ya empezado el siglo XXI identifican el famoso "corralito" como el evento que inauguró un nuevo marco ideológico que, si bien estaba signado en lo político por la desafección ciudadana y la pérdida de credibilidad de las

${ }^{3}$ Conviene recordar que El matadero de Esteban Echevarría funda la tradición literaria argentina justamente con el tema de la violencia como eje central. Por lo tanto, la elección que hace Bruzzone de este tema y su tratamiento lo ubica inevitablemente en diálogo directo con el canon argentino. 
instituciones públicas, también supuso la reconfiguración y el reinicio del espacio cultural que, potenciado por la democratización del acceso a contenidos culturales a través de Internet, creó un caldo de cultivo propicio para que los jóvenes intelectuales y escritores argentinos establecieran nuevas vías y plataformas para la circulación, promoción y producción del arte y la literatura al margen de los cauces tradicionales. El escritor Hernán Vanoli (a la sazón compañero de Bruzzone en la fundación y gestión de la editorial Tamarisco) resume ese cambio señalando que, mientras que los escritores nacidos entre los años 50 y los 60 "tienen la experiencia de un mercado editorial literario funcionando y de una cultura literaria con cierta relevancia social", los que empezaron a publicar en el siglo XXI tuvieron que reinventar el mercado y "asistieron a la implosión de las formas más fuertes de intercambio mercantil dentro de la industria cultural a través de la digitalización de los contenidos y de su fácil acceso, muchas veces gratuito (música, películas, libros, en un contexto donde la cultura literaria perdía muchas de sus funciones sociales" (146). Elsa Drucaroff ahonda en esta misma idea y en su ensayo crítico Los prisioneros de la torre (2011) explica que la gran diferencia entre la generación anterior y la presente tiene que ver con "las actitudes ante el oficio, los colegas, la difusión y el mercado" (180). Mientras que la generación anterior interpretó el mercado en términos competitivos, sin tejer alianzas por miedo a perder su sitio en la estrecha mesa que el mercado había dispuesto, la nueva generación cambia por completo esa limitada mirada y reinventa las reglas del juego a través de la autogestión de todo un entramado de colaboraciones, nuevas editoriales independientes, recitales, performances, charlas, exposiciones y talleres para crear un espacio para sus propias creaciones que esté abierto al consumidor local especializado. Uno de los ejemplos más conocidos es la editorial y cooperativa Eloísa Cartonera -famosa por fabricar libros a mano con materiales reciclados y que, posteriormente, se convertiría en modelo para otros muchos proyectos editoriales alternativos y autogestionados-, pero, además, surgen grupos de escritores que se convierten en gestores culturales, como los autodenominados "Quinteto de la muerte", "Carne argentina" o "Alejandría". Otros grupos deciden 
CATEDRAL TomAdA: Revista de crítica literaria latinoamericana / Journal of Latin American Literary Criticism Desacralizando el espacio de lo narrable: (pos)memoria, autoficción y mercado editorial en Los topos y 76 de Félix Bruzzone

fundar editoriales independientes para autoeditarse, y al ir creando una pequeña infraestructura para la difusión y venta de sus propios libros, también acaban dando espacio a la edición de otros textos de escritores noveles. Entre otros muchos, es el caso de sellos como La Creciente, Entropia o Tamarisco, el proyecto editorial cogestionado por Sonia Budassi, Violeta Gorodischer, Hernán Vanoli y el propio Félix Bruzzone (Drucaroff 181). A esta ferviente actividad editorial y cultural hay que añadir toda una batería de medidas estatales para apoyar el sector del libro implementadas durante el gobierno de Cristina Fernández de Kirchner que sin duda ayudaron a estimular la aparición de muchos de estos proyectos editoriales independientes. Ana Gallego señala que estas editoriales se convirtieron también en mediadores o "gatekeepers" (Marling, Thompson) que han funcionado como filtros y productores de obras con un "sentido nacional" y han ido influyendo tanto en "la forma y contenido de los textos, como en la creación de audiencias, es decir, de gustos que se filtran a otras instancias de legitimación como la crítica literaria, el periodismos cultural, los premios, el cine", etc ("Las narrativas del siglo XXI" 10). Esa orientación en el contexto argentino ha estado marcadamente inclinada hacia temas como el trauma del pasado, la reconstrucción de la memoria, la errancia o los fantasmas, y la autoficción ha sido elegida el vehículo discursivo predilecto para la articulación de la subjetividad de la generación de los hijos.

La aparición de los dos libros de Bruzzone en 2008 -junto con La casa de los conejos de Laura Alcoba ${ }^{4}$ - abrió nuevos canales de circulación que recorrerían posteriormente otros textos que abordan generacionalmente de manera similar el problema de la memoria, como pueden ser Soy un bravo piloto de la nueva China de Ernesto Semán (2011, Random House Mondadori), El espíritu de mis padres sigue subiendo por la lluvia de Patricio Pron (2011, Random House Mondadori), Diario de una princesa montonera $-110 \%$ verdad de Mariana Eva Álvarez (2012, Capital Intelectual) o Pequeños combatientes de Raquel Robles (2013, Alfaguara). Como ha desarrollado extensamente Marianne Hirsch a través del concepto de

${ }^{4}$ Hay que precisar que se trata de un caso diferente, ya que originalmente fue escrita en francés y publicada en 2007 en Francia. En 2008 fue traducida al español y publicada en la editorial Edhasa. 
"postmemoria", las novelas de estos jóvenes autores que pertenecen a la generación de los hijos de los desaparecidos están marcadas por la tensión inherente al proceso de rearticulación de una memoria propia del trauma (individual y generacional) que se construye forzosamente a través de una narración "mediada" por el relato (íntimo y público) de la generación anterior. Los núcleos de las diferentes tramas de estas novelas giran alrededor de un vacío en ese relato que interpela al protagonista y le exige que inicie una búsqueda o investigación para rellenar esos huecos a través de los fragmentos inconclusos y desdibujados de la memoria de la infancia, la cual es proyectada hacia el presente, alterando y cuestionando los límites de su propia identidad. En el contexto literario argentino, esta estructura fragmentada e inconexa que intenta reproducir los saltos laterales de la memoria ha hecho que la crítica señale una relación paternofilial entre César Aira y la producción narrativa de estos jóvenes autores. Sin embargo, Elsa Drucaroff señala que Aira, "prudentemente, nunca se metió con la represión del 76" y que, "en general, se ha cuidado mucho de trabajar literariamente con temas realmente conflictivos" (103). Más bien apunta a Rodrigo Fresán como el hermano mayor de la "Nueva Narrativa Argentina (NNA)" (17) y su Historia argentina (1991) como el punto de partida de una nueva narrativa "nada realista", "paródica", y con "la voluntad provocativa y políticamente incorrecta de revisar la historia reciente nacional" y entablar "una discusión nueva, necesaria y autoconsciente contra el discurso políticamente correcto de la izquierda, contra las entonaciones solemnes y crispadas de la literatura 'comprometida' y sus supuestas verdades deificadas e indiscutibles" (100-101). Concuerdo con este reajuste, pero, además, creo que en el caso concreto de Bruzzone y el tono delirante del protagonista de Los topos, convertido en un detective que por momentos deja de distinguir la realidad de la alucinación, hay que trazar una relación directa con la "ficción paranoica" de Ricardo Piglia y su alter ego Emilio Renzi. Sin embargo, cuando el propio Bruzzone es cuestionado por sus filiaciones, no duda en apuntar a Manuel Puig como modelo transgresor que "permite ver la literatura desde otro lugar no tan literario" ("Los siete locos parte II" 0:00 - 0:45), y también al docudrama Los rubios (2003), de Albertina 
CATEDRAL TomAdA: Revista de crítica literaria latinoamericana / Journal of Latin American Literary Criticism Desacralizando el espacio de lo narrable: (pos)memoria, autoficción y mercado editorial en Los topos y 76 de Félix Bruzzone

Carri, como el primer relato generacional en el que identifica la autoficción como el registro más apropiado para una nueva forma de dialogar con el complejo archivo sobre el que se construye la memoria.

Aunque algunos de los cuentos de Bruzzone aparecieron en antologías que han sido señaladas como nodos articulatorios de la NNA, como Buenos Aires / Escala 1:1 (2007, Entropía) o En celo (2007, Random House Mondadori), la verdadera entrada de Bruzzone en el campo literario como escritor fue en 2008, cuando sale en Tamarisco su primer libro, 76. El libro tuvo una estupenda acogida y se agotó en breve, lo cual llamó rápidamente la atención de los editores de Random House Mondadori Argentina -ahora Penguin Randon House Grupo Editorial-, que se pusieron en contacto con él para tantear la posibilidad de publicar una novela ("Los siete locos parte I" 3: 44 - 4:13). Finalmente, acabó publicando Los topos ese mismo año y en esa editorial, donde también publicaría sus novelas posteriores, Barrefondo (2010) y Las chanchas (2014). Por tanto, la importancia de 76 es la de tomar ese testigo del docudrama Los rubios y crear el primer texto literario que inaugura el relato generacional que reflexiona específicamente sobre las implicaciones sentimentales e ideológicas de crecer siendo hijo de desaparecidos. En cambio, el hito de Los topos radica en conseguir trasladar ese discurso desde una editorial independiente a la mayor casa editorial en español, que aprovecha el trabajo de mediación previo de Tamarisco y el éxito de 76 y no duda en cooptar el discurso memorialístico de la nueva generación y crear un nuevo nicho dentro del gran mercado de la memoria, sabiendo de antemano que encajará perfectamente entre el público -académico y no académico- acostumbrado a las diversas formas narrativas desde las que la generación anterior había tratado asuntos como el trauma, la memoria y el duelo en el Cono Sur. Tanto es así que, excepto Diario de una princesa montonera, todas las novelas citadas más arriba fueron publicadas también en Random House Mondadori o Alfaguara -ambos sellos pertenecientes en el presente a Penguin Random House Grupo Editorial. Por tanto, el caso de Bruzzone sirve como ejemplo paradigmático para ilustrar perfectamente cómo funcionan los circuitos del complejo biosistema 
mercadológico en el que las editoriales independientes realizan un trabajo de curación y creación de una serie de temas que van definiendo y construyendo el campo literario correspondiente -en este caso el argentino. Posteriormente, las grandes casas editoriales transnacionales se van nutriendo de ese trabajo de filtrado previo y aprovechan ese estudio de mercado que les llega ya hecho para ir seleccionando esos autores que han tenido ya cierto recorrido, confirmando y consolidando determinados temas - en este caso la posmemoria y el trauma- en los circuitos comerciales.

Sin embargo, el recorrido de la obra de Bruzzone durante estos primeros años no se limita a Argentina o al ámbito hispánico: Los topos se traduce al francés y 76, al alemán, lo cual ratifica esa imbricación indisociable del trabajo entre editoriales independientes y comerciales también en los procesos de internacionalización de la literatura en español fuera del ámbito hispánico. En Francia, Los topos es publicado por Asphalte, una editorial independiente especializada en literatura internacional en cuyo catálogo se encuentran también otros nombres de escritores de la generación de Bruzzone como Leo Oyola, Leandro Ávalos Blacha o J.P. Zooey y en Alemania es publicado por Berenberg Verlag, una editorial que cuenta con un prolijo corpus de autores canónicos latinoamericanos como Ricardo Piglia o Roberto Bolaño y que, además, está especializada en memorias y autobiografía, lo cual proporciona un marco y un pacto de lectura que elude la posibilidad de leer los relatos de 76 en clave totalmente ficcional. Además, en 2010, el cuento "Unimog” de su libro 76 apareció publicado en Alemania en la antología de jóvenes autores argentinos Asado verbal. Junge argentinische literatur, editada por Timo Berger y Rike Bolte en Verlag Klaus Wagenbach. La recepción de su obra en Alemania fue sin duda notable, entre otras cosas porque el campo literario alemán cuenta con una larga tradición vinculada a las narrativas del yo y el género testimonial y porque ciertas "nacionalidades latinoamericanas, como la argentina, se han fetichizado en el mercado global" ("Las narrativas del siglo XXI” 11). Tanto fue así que, en ese mismo año, Bruzzone fue merecedor del prestigioso premio de la Fundación Anna Seghers, que reconoce la 
CATEDRAL TomAdA: Revista de crítica literaria latinoamericana / Journal of Latin American Literary Criticism Desacralizando el espacio de lo narrable: (pos)memoria, autoficción y mercado editorial en Los topos y 76 de Félix Bruzzone

trayectoria literaria de autores jóvenes latinoamericanos con un marcado compromiso ético ${ }^{5}$ y que en los últimos años se ha convertido en uno de esos mediadores o gatekeepers que ha ido consolidando el flujo de nombres hoy ya consagrados como Cristina Rivera Garza, Gaudalupe Nettel, Lina Meruane o Yuri Herrera. Sin duda, el otro gran gatekeeper europeo es la Feria del Libro de Frankfurt y, justo en ese mismo año, Argentina era el país invitado y Bruzzone acudió como miembro de la delegación oficial que envió Argentina, por lo que pudo disfrutar de una plataforma inmejorable para promocionar su obra en el exterior. Toda esta repercusión internacional de su obra se traduce a su vez en un reconocimiento mayor dentro del campo argentino y acaba siendo seleccionado por el crítico y escritor Luis Chitarroni en la Revista $\tilde{N}$ del grupo Clarín como uno de los escritores jóvenes más importantes de la década. Además, al mismo tiempo que sus libros y su nombre empiezan a adquirir capital simbólico y político, su presencia en el espacio público sigue aumentando a través de la publicación de cuentos, crónicas y artículos en medios digitales tanto independientes como pertenecientes a grandes grupos mediáticos, como la propia Revista N, La mujer de mi vida, Anfibia, Página/12, El Interpretador, No Retornable o Traviesa.

No obstante, cuando le preguntan por su éxito en el exterior responde mostrándose como un escritor que ni siquiera es entendido localmente: "No tengo idea de cómo se leen mis libros afuera. A duras penas puedo ponerme de acuerdo con lectores mucho más cercanos. Hay lecturas de lo más insólitas" (Martín Caamaño). A pesar del reconocimiento del público y de la crítica local e internacional, Bruzzone siempre muestra una actitud o "poética de la resistencia" (“Comienzos de..." 6) hacia las políticas homogeneizadoras de las grandes casas editoriales y sus formas de promoción, y por eso siempre ha mantenido un pie

${ }^{5}$ Según las propias bases de la convocatoria y de acuerdo con la propia trayectoria de la escritora alemana, quien pasó gran parte de su vida exiliada en México, el propósito del premio es "la promoción de autores jóvenes poco conocidos de habla alemana y de América Latina" y se destina a autores que "desean contribuir, a través de los medios artísticos, al surgimiento de una sociedad humana más justa que tenga como centro la tolerancia y la colaboración entre diferentes culturas". Puede consultarse en el siguiente link http://www.anna-seghers.de/stiftung.php 
dentro de los circuitos independientes. En 2013, decide reeditar 76 de nuevo en una editorial argentina independiente, Momofuku, añadiendo dos relatos nuevos. Es evidente que la imagen que quiere proyectar no es la de un autor tradicional consagrado absolutamente a la escritura - entre otras cosas, porque la precariedad y neoliberalización del mercado en la actualidad ya no lo permite en la gran mayoría de los casos-, y por eso no duda en presentarse en las solapas de sus libros como escritor, editor, docente de enseñanza primaria y en talleres de escritura creativa, y limpiador de piletas, a partes iguales. De hecho, en 2017, publica en otra editorial independiente, Editorial Excursiones, Piletas, un libro de crónicas donde vuelca las reflexiones y anécdotas que le han ido surgiendo durante su trabajo como piletero, que previamente fue difundiendo a través de Facebook. Por tanto, además de confirmarse el patrón de crear una editorial independiente para autopublicarse y publicar textos que no encuentran su lugar en los circuitos de los grandes conglomerados editoriales, en el caso de Bruzzone se confirma también otra tendencia común entre escritores jóvenes latinoamericanos que empiezan a adquirir cierto reconocimiento: la bicefalia editorial. Es decir, suelen publicar poesía, crónicas y libros de relatos en editoriales independientes mientras que reservan las novelas para editoriales con más visibilidad. Por un lado, esto viene a corroborar los diferentes criterios de publicación entre editoriales independientes y los grandes conglomerados y cómo van operando entre las tensiones propias de los mercados nacionales y transnacionales, pero al mismo tiempo revela un posicionamiento político consciente por parte de los propios autores, que deciden usar el capital simbólico que les aporta una plataforma transnacional para transfundirlo a un ecosistema literario y cultural realmente independiente con el que se sienten comprometidos y en deuda.

De este modo, Bruzzone decide ser un escritor en continua contingencia, entrando y saliendo con cierta naturalidad de los diferentes circuitos mercadológicos, de la tradición argentina y de su propia memoria e identidad. Esa actitud extrapolada a su narrativa lo lleva a transgredir continuamente esa difusa y delgada línea entre la vida y la fícción o entre lo real y lo onírico, o incluso negarla 
CATEDRAL TomAdA: Revista de crítica literaria latinoamericana / Journal of Latin American Literary Criticism Desacralizando el espacio de lo narrable: (pos)memoria, autoficción y mercado editorial en Los topos y 76 de Félix Bruzzone

o cambiarla de sitio a su antojo con ese aire gamberro, escurridizo y provocador de quien se resiste a ser encasillado en un lado $u$ otro, y lo ha posicionado como uno de los escritores jóvenes más influyentes y con mayor proyección internacional de su generación.

\section{Los topos y 76 o cómo autoficcionar y parodiar la historia y la identidad}

En casos como el de Bruzzone, en el que la expresión de lo íntimo y lo subjetivo se convierten en un acto político por parte de un autor que es reconocido como una figura pública, es absolutamente fundamental tener en cuenta algunos datos de la vida del autor que pueden ser determinantes para arrojar luz y entender cabalmente cuáles son las implicaciones ideológicas de su posicionamiento respecto al tema de la memoria y el papel de los hijos de los desaparecidos en su obra. Bruzzone nació en agosto de 1976, cuando su padre ya llevaba cinco meses desaparecido. Su madre desaparecería tres meses después de su nacimiento. Tanto su novela Los topos como su colección de relatos cortos 76 (año de su nacimiento y del inicio de la dictadura militar) tienen en común que están narrados en primera persona, el narrador y protagonista nunca es identificado con un nombre propio y es hijo de desaparecidos. Ambos libros pueden leerse perfectamente como textos separados, pero juntos conforman un tejido narrativo desde el que Bruzzone propone al lector reconstruir el puzzle de su memoria a través de itinerarios de lectura llenos de idas y venidas entre la novela y los diferentes relatos. Además, el anonimato del narrador-protagonista junto con la extensa información paratextual sobre la biografía de Bruzzone dan cuenta de una estrategia narrativa y mercadológica que parte del propio autor (aunque seguramente también haya sido consensuada con los editores) y que condiciona irremediablemente que el lector identifique y confunda la voz narrativa con la voz del propio autor, creando de este modo una lectura en clave autoficcional. Es decir, en un extremo del eje realidadficción tendríamos la autobiografía, donde nos encontramos con un pacto tácito y 
explícito en el que el autor se compromete a contar su vida como "verdad" y el lector, además, entiende que la voz del narrador-protagonista se corresponde con la del propio autor del libro; y en el otro extremo estarían los relatos que no le dan al lector ningún margen para acogerse a una interpretación de los hechos narrados que no sea netamente ficcional. Como explica Philippe Gasparini, estos dos modelos opuestos promueven una "lógica binaria tranquilizadora" (179) en la que el lector no tiene que elegir ni replantearse los términos de ese contrato en ningún momento. En cambio, la autoficción rompe ese sistema binario y propone una tercera vía intermedia e híbrida en la que "no es posible discernir lo fabulado de lo realmente acontecido, generando así, una narración de tipo paradójico (no es ni autobiografía ni novela, o, si se quiere y como se ha repetido tantas veces, que es ambas cosas a la vez)" (Casas 98). Esta paradoja tiene lugar dentro de un tercer pacto de lectura mixto en el que el lector, aunque no puede evitar oscilar entre los dos extremos del eje y preguntarse qué parte habrá sido realmente vivida por el autor y cuál fabulada, llega a la conclusión de que no hay posibilidad de saberlo y que, por tanto, la incertidumbre y la "ambigüedad" (Alberca) es la única certeza que articula el sentido del relato y esa modalidad discursiva. La autoficción, por tanto, se brinda como un vehículo privilegiado "para plasmar narrativamente las ambigüedades, contradicciones y recovecos tanto de una memoria indirecta y fluctuante como de una identidad quebrada" (Logie 78), que son dos polos por los que oscila continuamente el discurso del protagonista de 76 y Los topos.

En el caso de Bruzzone, al mismo tiempo que presentarse como hijo de desaparecidos lo legitima como una figura pública con autoridad moral para opinar desde la perspectiva de los hijos, la autoficción le permite subvertir la presunción de verdad y desautoriza una lectura única de su relato -y, por ende, también expone la imposibilidad de articular una narrativa totalizadora que represente a todas las víctimas. Por tanto, su condición de hijo de desaparecidos no es un dato menor, ya que le da legitimidad para narrar las secuelas de la desaparición con una libertad adquirida por derecho, permitiéndose así el lujo de poder llevar un tema tan sensible hacia lugares menos cómodos protegiéndose de las críticas de quienes intenten 
CATEDRAL TomAdA: Revista de crítica literaria latinoamericana / Journal of Latin American Literary Criticism Desacralizando el espacio de lo narrable: (pos)memoria, autoficción y mercado editorial en Los topos y 76 de Félix Bruzzone

juzgar su irreverencia. Esta postura de Bruzzone, en la que a través de la hibridación de géneros y la confusión del concepto de autoría desafía la posibilidad de transmitir una verdad única y totalizadora expresada en un texto por un autor, encaja a la perfección en lo que Josefina Ludmer ha definido como "el fin del ciclo de la autonomía literaria":

Estas escrituras no admiten lecturas literarias; esto quiere decir que no se sabe o no importa si son o no literatura. Y tampoco se sabe o no importa si son realidad o ficción. Se instalan localmente y en una realidad cotidiana para 'fabricar presente' y ese es precisamente su sentido[....] Aparecen como literatura pero no se las puede leer con criterios o categorías como autor, obra, estilo, escritura, texto y sentido. No se las puede leer como literatura porque aplican a 'la literatura' una drástica operación de vaciamiento: el sentido (o el autor, o la escritura) queda sin densidad, sin paradoja, sin indecibilidad, 'sin metáfora', y es ocupado totalmente por la ambivalencia: son y no son literatura al mismo tiempo, son ficción y realidad. $(41-42)$

Tanto es así, que Bruzzone decide sobrepasar ese tercer pacto de lectura autoficcional ambigua. En la primera parte de Los topos, nos encontramos con un relato que puede parecer autoficcional y que incluso, por momentos, se acerca al género testimonial ${ }^{6}$. Sin embargo, a medida que avanza la historia y llegamos a la segunda parte, el narrador acaba subvirtiendo este registro a través de la parodia y la mezcla con otros géneros literarios como el policial y el fantástico. Se rompe ese pacto de lectura que previamente ya rompía la autoficción y el lector se contagia de

${ }^{6}$ El género testimonial tiene un carácter historiográfico, pero a la vez subjetivo; es decir, es un género híbrido que mezcla la ficción con la historia. Suele presentar una narración en primera persona en la que el protagonista del relato explica cómo fue su experiencia personal en relación con una serie de sucesos históricos reales. La dimensión del yo cobra una relevancia vital y se articula mediante la rememoración de vivencias, la valoración personal de unos hechos casi siempre de carácter aflictivo o traumático. El relato está mediado, escrito y editado por alguien que entrevista y elige qué elementos de ese testimonio deben ser rescatado e inmortalizados. 
la paranoia del narrador y acaba desconfiando de todo lo que está leyendo. Por tanto, lleva su objetivo radical de ruptura de ese sistema de "autonomía" de la literatura coherentemente hasta el final: no propone sustituir el discurso de la generación militante por uno nuevo, como puede parecer al principio, sino que le da un nuevo giro de tuerca al "giro autobiográfico" (Giordano) que termina rompiendo la rueda y la matriz ideológica que la sustenta. La cuarta vía, la vía de Bruzzone, es la radical imposibilidad de confiar en cualquier relato.

Al igual que el propio Bruzzone, el protagonista de Los topos (y también en el relato "Una casa en la playa") es criado desde que es un bebé por sus abuelos maternos en la casa familiar en Moreno. El comienzo de la novela nos presenta al protagonista haciendo memoria de algunos recuerdos de su infancia y, por el tono, parece anunciarnos, en principio, un relato de corte realista:

Mi abuela Lela siempre me dijo que mamá, durante el cautiverio en la ESMA, había tenido otro hijo. Varias veces la oí discutir del tema con mi abuelo. Ellos se iban al fondo, al zapallar, y hablaban de todo lo que yo no tenía que saber. Pero a veces me escondía entre las hojas de los zapallos, que para mí eran un lugar de juego, ... y cuando mis abuelos llegaban para hablar los escuchaba. (11)

Como vemos desde el comienzo, el protagonista hace alusión a los recuerdos de lo que escuchó cuando era niño y de lo que otros le contaron. Como bien explica Hirsch, la principal característica de la posmemoria es la mediación, ya que, para ir configurando el mosaico de la memoria, se usa lo que no se ha vivido directamente. Es decir, las estrategias de la posmemoria consisten en usar los recuerdos transmitidos por otras personas, entidades u objetos personales para ir articulando con esos fragmentos un relato autónomo con sentido:

Postmemory describes the relationship of the second generation to powerful, often traumatic, experiences that preceded their births but that 
CATEDRAL TomAdA: Revista de crítica literaria latinoamericana / Journal of Latin American Literary Criticism Desacralizando el espacio de lo narrable: (pos)memoria, autoficción y mercado editorial en Los topos y 76 de Félix Bruzzone

were nevertheless transmitted to them so deeply as to seem to constitute memories in their own right. ... Postmemorial work, strives to reactivate and reembody more distant social/national and archival/cultural memorial structures by reinvesting them with resonant individual and familial forms of mediation and aesthetic expression. ... Family photos, and the familial aspects of postmemory, would tend to diminish distance, bridge separation, and facilitate identification and afiliation. (109-16)

En su libro Tiempo pasado: cultura de la memoria y giro subjetivo (2005), Sarlo resume las características de este concepto combinando lo establecido por Hirsch y James Young y puntualiza que, aunque los dos autores coinciden en que la posmemoria es mediada porque los recuerdos son indirectos, toda memoria salvo algunos recuerdos específicos y puntuales- se configura a través de la mediación del discurso de terceros y también por lo que cuentan los medios de comunicación, por lo que la pensadora argentina ve innecesario el uso del prefijo "pos". Sarlo concluye que tanto Young como Hirsch dan por sentado que cuando se habla de posmemoria se habla de hechos traumáticos y que, por tanto, la utilidad del concepto se limita a un campo demasiado reducido. Coincido en señalar que el prefijo "pos" se ha lexicalizado en los últimos años ante la incapacidad de crear nuevas categorías epistemológicas originales y que sus connotaciones temporales pueden despistarnos de su verdadero trasfondo ${ }^{7}$, pero también es cierto que las reservas reales de Sarlo hacia este concepto teórico vienen motivadas por una filiación personal a una noción estética borgeana que valora cualquier aparición de la primera persona como un acto narcisista y una violencia innecesaria que debe ser eludida a toda costa a menos que se tenga una justificación narrativa de peso. Sin

${ }^{7}$ En "Pantallas de papel: remediación y transmemoria en Crónica de viaje de Jorge Carrión" (Página y Pantalla: interferencias Metaficcionales. Teresa Gómez Trueba y María Martínez Deyros (Coords.) Trota, 2018), profundizo en esta idea y propongo el término de "transmemoria" justamente para hacer énfasis en los procesos de transformación y articulación de la memoria y establezco un diálogo con otros conceptos críticos en el campo de los Memory Studies como "multidirectional memory" de Michael Rothberg o "travelling memory" de Astrid Erll. 
embargo, aunque el concepto de posmemoria haya sido acuñado en específico para abordar la producción cultural y memorialística en torno a la generación de los hijos del Holocausto judío, creo que es perfectamente proyectable al contexto de las posdictaduras en el ámbito hispánico. Primero hay que entender que en las narraciones de la posmemoria se reconstruye el pasado desde posiciones eminentemente emocionales antes que racionales y esto condiciona la elección de una modulación autoficcional y subjetiva. Como expresa Josefina Ludmer en Aqui América Latina (2010), en el contexto argentino, "cuando se habla de memoria se habla de una relación genealógica y familiar a cargo de Madres, Abuelas, Hijos, Familiares"; y, "como el sujeto se define como familiar, la memoria es afecto" (73). Por tanto, estos relatos cobran sentido al desarrollarse precisamente dentro del contexto familiar, un espacio afectivo privilegiado que ayuda a preservar la transmisión de la memoria en contextos donde las libertades han sido restringidas. Es decir, hay que tener en cuenta que el concepto de posmemoria adquiere toda su capacidad como categoría simbólica dentro de los procesos colectivos de reconstrucción de la memoria sobre un pasado traumático vinculado a un genocidio porque las víctimas no están lidiando simplemente con un episodio trágico personal o familiar, sino que se enfrentan directamente a la violencia ejercida por el aparato del estado. El contradiscurso de la posmemoria trata de desmantelar un relato institucionalizado durante décadas, intenta superar todo un olvido sistemático y borrado oficial de un determinado sector de una población al que se le negó durante años la posibilidad de articular su identidad y su voz públicamente. Como replica Leticia Gómez, "en situaciones normales no se borran generaciones completas por medio de desapariciones forzadas de personas, ni hay planes precisos y eficaces para ocultar, destruir y prevenir el registro de información" (39). Es decir, si ya normalmente la memoria es bastante fragmentaria y selectiva, en un contexto dictatorial militar se hace aún mucho más complicado archivar y registrar la memoria, ya que desde el poder se sistematiza el control de la información y se borra al otro literalmente a través de un discurso que se convertirá en la historia oficial. 
CATEDRAL TomAdA: Revista de crítica literaria latinoamericana / Journal of Latin American Literary Criticism Desacralizando el espacio de lo narrable: (pos)memoria, autoficción y mercado editorial en Los topos y 76 de Félix Bruzzone

El detalle de que el narrador de Los topos sitúe el comienzo del relato en los recuerdos de su infancia tiene mucha importancia en este contexto de la posmemoria. Según observa Hirsch (115), existe una "generación 1.5” (es decir, una generación que está a caballo entre la primera y la segunda) en la que la figura del niño superviviente es vital para entender el desdibujamiento entre generaciones, ya que, aun siendo testigos directos, los niños no son plenamente conscientes del alcance de lo que sucede a su alrededor ni tienen la posibilidad de posicionarse. Siguiendo con la idea de un acceso mediado al pasado, sobre todo en lo que tiene que ver con la herencia de los recuerdos, el protagonista de Los topos accede a su memoria a través de las historias que su abuela materna le fue contando durante su infancia y adolescencia. Esa herencia incluye una marca identitaria, la orfandad, que se acaba expresando como una especie de predestinación y una necesidad existencial de continuar con la búsqueda que inició su abuela de su supuesto hermano robado al nacer - del que, por otra parte, nunca tendremos certeza plena de si realmente existió más allá de las conjeturas del protagonista. La tensión que articula el ritmo del relato es precisamente la combinación, por un lado, de esa fuerza fatídica que lo predestina a dibujar ciertos recorridos y cartografías por las que se supone que debe transitar un hijo de desaparecidos en busca de respuestas, y, por otro, la errancia como la forma elegida por el protagonista para rebelarse contra ese destino y construir su propia subjetividad al margen.

El narrador-protagonista continúa hablando sobre cómo su abuela empezó a buscar a su hermano: "Mi abuelo murió sin nunca darle demasiada importancia a lo que decía mi abuela sobre mi supuesto hermano nacido en cautiverio. Pero ella siempre insistió, sola, y supongo que ya en el velorio de mi abuelo pensaba en salir a buscarlo" (12). Efectivamente, después de la muerte del abuelo, la abuela decide por fin empezar una búsqueda sistemática y seria, sin las restricciones de nadie: decide vender la casa familiar y mudarse lo más cerca posible de la ESMA y dedicar todo su tiempo y recursos económicos a ese objetivo. En un principio, el protagonista, aún muy joven, prefiere disfrutar de la libertad que le da la ausencia de su abuelo para entrar y salir de casa a su antojo en lugar de involucrarse en la 
búsqueda de su hermano, e incluso tacha la determinación de su abuela de "delirante" (13). Sin embargo, su relación con su propia identidad como huérfano de desaparecidos cambia cuando conoce a Romina, quien se convertirá en su novia y empezará a militar en $\operatorname{HIJOS}^{8}$ aun sin tener ningún familiar desaparecido, únicamente "como gesto de compromiso" (15) hacia su relación con él y para evidenciar que la recuperación de la memoria no se trata de un espacio exclusivamente personal y familiar, sino social y público. Aunque en un primer momento el protagonista se muestra atraído hacia la idea de formar parte de la asociación (e incluso fantasea con hacer escraches como "forma de revancha o de justicia por mano propia" o "comprar un Falcon y salir con mis amigos a secuestrar militares" 17), tanto en Los topos como en el relato "Sueño con medusas" evidencia sus reservas con respecto al discurso militante sectario de HIJOS. Siente que su relación con Romina y otros militantes de HIJOS lo está distanciando de sus amigos de toda la vida y, además, Romina (y por ende también HIJOS) insiste demasiado en establecer unos términos en la relación en clave de salvadora-salvado con los que no se encuentra cómodo. Así que, finalmente el protagonista decide no militar y alejarse de la asociación y, paulatinamente, también de su novia.

A partir de ahí se precipitan una serie de acontecimientos (su novia le cuenta que está embarazada, decide abortar, rompen la relación, muere su abuela y él vende su apartamento) que ponen su vida patas arriba y lo llevan a pasar por un momento de depresión e introspección en el que las pesadillas se van mezclando con los recuerdos y la realidad:

No recuerdo cuándo empezaron las pesadillas. Lela había muerto, eso es seguro porque fue por la época en que vinieron a tasar y a poner en venta el departamento. Yo, a decir verdad, no estaba muy bien, pero como todo había pasado tan rápido - pelea con Romina, embarazo, aborto, muerte de

${ }^{8}$ Acrónimo de Hijos e Hijas por la Identidad y la Justicia contra el Olvido y el Silencio. Es una organización pro derechos humanos en Argentina que lucha contra la impunidad de los implicados en crímenes de lesa humanidad, y por la recuperación de la memoria democrática y la restitución de la identidad de los familiares desaparecidos. 
CATEDRAL TomAda: Revista de crítica literaria latinoamericana / Journal of Latin American Literary Criticism Desacralizando el espacio de lo narrable: (pos)memoria, autoficción y mercado editorial en Los topos y 76 de Félix Bruzzone

Lela, puesta en venta del apartamento- todavía no sabía por dónde empezar a deprimirme. La puesta en venta, igual, fue buena noticia. Pero no tan buena, porque si lo de las pesadillas empezó por esa época tiene que haber sido algo malo. (Los topos 31)

Esta marcada presencia de lo onírico en su vida también aparece en "Sueño con medusas", donde el protagonista intenta usar la interpretación de una serie de imágenes recurrentes en sus sueños como mecanismo para procesar el desfase entre los recuerdos mediados por su abuela y la información que está recabando en su propia búsqueda ya siendo adulto:

Mi abuela Lela decía que cuando llamaron a la puerta para avisarle de lo de mamá y papá el cielo estaba despejado y la luz del sol, que era fuerte y caliente porque era verano, se convirtió en una especie de medusa que empezó a chocar contra los vidrios hasta deshacerse en medusas más pequeñas [...], como una lluvia débil pero insistente, pegajosa, que no dejaba pensar. Mucho después, cuando Lela murió y revisé los diarios de la época para saber cómo había sido el día en que mamá y papá desaparecieron, vi que en realidad el tiempo había sido inestable y que hasta habían caído tormentas de intensidad en buena parte del conurbano. Así que pensé que mi abuela, por alguna razón, había invertido las cosas: el agua había estado fuera, la luz adentro, y ella había sacado la luz hasta atrás de las ventanas y había hecho entrar toda el agua. Después también pensé que ella, aquel día, había salido a llorar al patio. (69)

El relato continúa ahondando en esta obsesión por las medusas y los motivos acuáticos y el protagonista explica que la primera vez que se atrevió a hablar de esas medusas, de sus fantasmas, fue en la primera reunión de HIJOS a la que fue por la insistencia de Romina: "me preguntaron algo y lo primero que se me ocurrió fue lo de las medusas. Yo sueño con medusas, dije, y como todos me 
miraron con interés seguí ... Estaban las que me perseguían con ruido a hierros viejos y a óxido, las que me provocaban náuseas al tocarlas, las que me despertaban en medio de la noche y me hacían sentir que todo alrededor era el sistema digestivo de una medusa" (72). Estos episodios fantástico-oníricos son el primer aviso para el lector de que se va a romper el pacto realista y que debe empezar a desconfiar de la información que nos proporciona el protagonista y del orden cronológico de la misma.

Volviendo a Los topos, en mitad de ese proceso depresivo y en el que todo empieza a torcerse, conoce a Maira, una "travesti"9 (25) también hija de desaparecidos, que se convierte en su confidente, en la persona que le ayuda a sobrellevar su crisis, y con quien iniciará una complicada relación sentimental. Sin embargo, de un día para otro, Maira desaparece misteriosamente sin dejar rastro. De este modo, nos encontramos a un protagonista totalmente perdido y solo, sin ningún tipo de vínculo afectivo con un ser querido después de su ruptura con Romina y de la desaparición de Maira. Está completamente escindido y desterritorializado, sin saber qué le pasó a su madre, sin saber si su hermano está vivo o no o si alguna vez existió o dónde está Maira. Incluso ha vendido el pequeño apartamento en el que había pasado los últimos años con su abuela. Necesita reubicarse y poner algunas cosas en claro, por eso decide volver al sur, a Moreno, donde se crio con sus abuelos. Allí se reencuentra su antigua casa familiar que sorprendentemente está deshabitada y totalmente abandonada, así que decide arreglarla y ocuparla sin pensárselo demasiado. La casa, que claramente alude a los fundamentos de su identidad, está en ruinas; por eso, reconstruirla es una manera también de rehabilitarse a sí mismo.

Después de esa reconciliación consigo mismo y con sus raíces, deja de luchar contra su destino y toma la determinación de volver a Buenos Aires e invertir todo su tiempo y sus recursos en la búsqueda de Maira y también de su hermano porque "empecé a sentir la necesidad de confirmar u olvidar para siempre la versión

\footnotetext{
${ }^{9}$ Uso ese término porque es el utilizado en la novela y en el relato "La chica oxidada".
} 
CATEDRAL TomAdA: Revista de crítica literaria latinoamericana / Journal of Latin American Literary Criticism Desacralizando el espacio de lo narrable: (pos)memoria, autoficción y mercado editorial en Los topos y 76 de Félix Bruzzone

de Lela sobre mi supuesto hermano nacido en cautiverio, como si las dos búsquedas tuvieran algo en común, como si fueran parte de una misma cosa o como si fueran en realidad, lo mismo" (41). Esto, sumado a otros indicios anteriores ("por algún motivo sentía que a Maira podía decirle la verdad”, 26) nos lleva directamente al momento en el que el protagonista ata cabos: no sólo descubre que Maira era en realidad un "topo" que supuestamente se travestía para captar extorturadores y matarlos, sino que llega a la conclusión de que Maira es su hermano desaparecido que tanto buscaba su abuela. El momento de la revelación ocurre mientras prepara una torta de cumpleaños, que es la ocupación a la que se había dedicado profesionalmente junto con su abuela en los últimos años y por lo que de alguna forma se intuye la guía espiritual de Lela detrás de la búsqueda. Para agregarle una guinda socarrona a la torta, está personalizada con los dibujos de Batman y Robin, una clara referencia queer: "No tardé en descubrirlo: en los ojos, en los pómulos y en la forma chata del mentón, eran evidentes los rasgos de Maira. O no, más que a Maira, Robin se parecía a mí. Me senté. Era imposible que fuéramos hermanos” (67). El protagonista sigue mirando la torta y divagando sobre esta posibilidad: "La escena, en algún momento, cobró vida: papá era Batman y Maira y yo éramos Robin. Un Batman y dos Robin. La aventura que emprendíamos juntos consistía en caer por sorpresa a una reunión de mafias aliadas que estaban en la cuenta final para un devastador asalto a Ciudad Gótica" (69). Robin-Maira y Batman-papá acaban discutiendo sobre cuál es la mejor estrategia para acabar con esos peligrosos mafiosos, pero la discusión se convierte en un debate generacional entre fuerzas progresistas con diferentes perspectivas en el que los jóvenes le acaban reprochando a los mayores "todos sus años de ausencia" (71).

Es justo aquí donde el relato empieza a virar hacia el género policial, el género de espías y también el fantástico: el protagonista cree encontrar a Maira en Moreno y se convierte en un detective que sigue sus pasos, pero, en pleno proceso de seguimiento y espionaje, acaba sintiéndose observado, paranoico, perseguido y parte de una conspiración. Empieza a dudar de todo, incluso piensa que todo forma parte de un "complot antihomosexual internacional" (56) y que la propia Maira le 
ha tendido una trampa. En mitad del delirio y después de haberse tirado de un tren en marcha, acude a la asociación HIJOS para que le digan si saben algo de Maira. Allí le confirman que Maira llevaba años colaborando con ellos, pero de manera independiente, moviéndose siempre de un sitio para otro para no ser encontrada, haciendo justicia a su modo, y que efectivamente nació en cautividad y buscaba a su hermano. Aunque no han encontrado su cuerpo, sospechan que puede haber sido asesinada y tienen un posible sospechoso: El Alemán, un extorturador de la dictadura conocido por su obsesión con las travestis. La confrontación del dossier completo con los datos sobre Maira que le dan en HIJOS lo hace delirar hasta la alucinación esquizoide:

Después de tantos datos documentados, inobjetables, y que parecían flotar como verdades eternas en el interior y alrededor de las miradas de los que me habían atendido, empecé a rascarme las axilas. No me picaban, pero al tiempo de empezar a rascarlas sí, mucho, una picazón dura, no agradable como la que provocan a veces los mosquitos sino agresiva, como si yo hubiera apoyado las manos en un hormiguero y miles de atléticas guerreras hubieran saltado a morderme los brazos. (61)

Como cualquier relato policial, el enigma por resolver debe volverse el centro de la narración y debe concentrar todos los pensamientos del detective. Nuestro protagonista, efectivamente, establece el enigma del caso de la desaparición de Maira como su única misión y el eje del relato. Ante tal obsesión, no duda en infiltrarse y participar de ese juego de identidades y corporalidades que da sentido al título de la novela, así que decide travestirse para localizar y matar a El Alemán y, por fin, vengar a Maira. Siguiendo lo que Rolland Barthes plantea en su libro $S / Z$ sobre la narrativa detectivesca, el enigma siempre plantea una serie de preguntas al lector y su resolución suele postergarse con el objetivo de crear el suspense que mantenga en vilo la atención del lector hasta el final. Sin embargo, en este caso, se les da a los lectores el enigma y se crea una atmósfera de suspense y 
CATEDRAL TomAdA: Revista de crítica literaria latinoamericana / Journal of Latin American Literary Criticism Desacralizando el espacio de lo narrable: (pos)memoria, autoficción y mercado editorial en Los topos y 76 de Félix Bruzzone

tensión, pero el elemento paródico rompe por completo esas expectativas creadas por el género policial y, una vez más, engaña al lector: en el colmo del delirio, en lugar de hacer justicia, no sólo acaba siendo secuestrado por El Alemán, sino que, en un claro caso de síndrome de Estocolmo, se acaba enamorando de él e incluso se somete a una operación quirúrgica para completar su transición. Los hechos se precipitan a una velocidad vertiginosa y ante la ausencia de un trabajo verosímil y serio que explique esa repentina relación, el narrador-protagonista se limita a justificarse argumentando que sus expectativas no se han cumplido: "Yo siempre esperaba que alguna vez él empezara con sus maltratos, pero no sólo no me maltrataba sino que las cosas iban cada vez mejor" (153). No obstante, cuando menos se lo espera, cuando más enamorado ${ }^{10}$ está, le da una paliza, lo secuestra y se lo lleva a vivir con él. Para el protagonista, este proceso trasformativo de su identidad de género está estrechamente imbricado con su propia identidad como hijo de desaparecidos y se experimenta como un círculo que por fin se cierra. Haber transicionado y convertirse en la mujer de El Alemán es una forma de encontrar a Maira y a sí mismo, como si ambos fueran dos caras de la misma moneda, dos Robin: "llegaba a mi pieza y cerraba los ojos y me encontraba con Maira y le decía: ... ahora sé que vine a hacer lo que vos no pudiste, a ser feliz junto al hombre que iba a ser tuyo pero que ahora me tocó a mí, alguien en verdad imbatible, hermano, porque ahora que te veo, y cada vez que te veo, sé que somos hermanos, y vos lo sabías" (154-5). La violencia del final del relato y la sumisión del protagonista a esa situación se puede interpretar claramente como una forma de saldar la deuda o de purgar la culpa por no haber sido él quien desapareció en lugar de sus padres o Maira, como una forma de quedar en paz con sus fantasmas del pasado. Sin embargo, en mi opinión, ese sacrificio no solo tiene consecuencias personales e íntimas, sino sociales y colectivas. Transformar su identidad se convierte en un acto político que pretende tener un impacto real en la sociedad, ya que se sacrifica para que no haya más desapariciones y El Alemán no siga matando. Mientras que HIJOS

${ }^{10}$ Uso el género gramatical masculino únicamente porque el protagonista sigue refiriéndose a sí mismo en masculino. 
no consigue aglutinar transversalmente a las víctimas, su cuerpo y su identidad se convierten solidariamente en un tejido social colectivo.

En este relato vertiginoso, delirante e intencionalmente ambiguo, la confusión y el juego se convierte en un elemento central en la trama: la identidad de género subvierte los límites heteronormativos, la fantasía se funde con lo real y lo serio se torna parodia que irremediablemente hacen que el lector dude $\mathrm{y}$ desconfíe del narrador, cuya paranoia se acrecienta a medida que avanza el relato: “El Alemán podía ser el padre de Maira, mi padre, el torturado, el entregador, el torturador, el boxeador golpeador de travestis ... Su vida en los pueblos del sur podía haber sido la del desaparecido con vida, la del exiliado interno, la del perseguido" (174). Nadie es quien dice o parece ser; hasta se sugiere la posibilidad de que su padre haya sido un topo de la dictadura, o incluso quien delatara a su madre (Los topos 68-9). En un primer nivel de lectura, el tratamiento que Bruzzone hace de la identidad de género es sumamente problemático por su propio lugar de enunciación. Sin embargo, el propio Bruzzone ha aclarado que, "el tema de las travestis y la prostitución, a fines de los 90, era un tema candente [en el debate social]. De hecho, se las desplazó varias veces porque estaban en lugares 'inconvenientes'. Todo eso está presente [en Los topos y “La chica oxidada"], pero también el estereotipo sobre qué es un travesti. En la novela no hay un trabajo serio sobre el travestismo, sino en función de ese estereotipo. Se está tomando algo que viene de lo bajo, de lo popular, de los medios" ("Cuentomilibro" 6:45-7:42) para ridiculizarlo y señalar que los clichés y estereotipos que la ideología reaccionaria de la dictadura impuso se siguen reproduciendo en el presente. Por tanto, la inclusión de la transexualidad no funciona únicamente como metáfora reconocible para expresar la identidad como performance o lo contingente frente a formas discursivas monolíticas y conservadoras, sino que le sirve para expresar que la violencia de la dictadura, el exterminio sistemático del otro, llega hasta el presente. Por eso, El Alemán es un torturador de la dictadura que sigue haciendo lo mismo impunemente en democracia. Desde la dictadura hasta hoy, cientos de mujeres 
CATEDRAL TomAdA: Revista de crítica literaria latinoamericana / Journal of Latin American Literary Criticism Desacralizando el espacio de lo narrable: (pos)memoria, autoficción y mercado editorial en Los topos y 76 de Félix Bruzzone

transgénero han sido asesinas o están desaparecidas ${ }^{11}$. Estas desapariciones no han sido reivindicadas por las asociaciones mayoritarias como HIJOS, y con ello han contribuido a invisibilizar que el exterminio también estuvo basado en la identidad de género, convirtiendo así el derecho a la memoria en "un privilegio heterosexual"12. Por tanto, Bruzzone no sólo traza una línea de continuidad entre la violencia de la dictadura y la del presente, sino que también acusa directamente a esas organizaciones de colaborar con esa violencia al no revisar su propio discurso y hacerlo más flexible e inclusivo. Es decir, hay una denuncia clara: la búsqueda de justicia por las desapariciones de la dictadura no puede hacer que haya un ensimismamiento que niegue las desapariciones en el presente. No puede haber desaparecidos de segunda clase. En cualquier caso, coincido con Gabriel Gatti en que Bruzzone busca ser "políticamente incorrecto y sociológicamente sugerente" no sólo por su tratamiento de la identidad queer y la corporalidad, sino porque a través de estos "juegos con los nombres y con los cuerpos" (176) está subvirtiendo tanto los límites heteropatriarcales y tradicionales de la identidad de género como la identidad de los hijos de desaparecidos configurada a partir de una memoria fragmentada y mediada. Por tanto, está planteando una noción de identidad múltiple (no binaria) y líquida que no se limite a una determinada filiación social o de género.

Como bien dice Benjamin en la cita del principio, Bruzzone es consciente de que la irrisión que se desprende de la parodia carnavalesca de corte bajtiniano es uno de los mejores mecanismos para subvertir los corsés sociales y, en el contexto argentino, para activar el pensamiento crítico que desde el espacio público cuestione las lecturas tradicionales del trauma y el discurso sobre la identidad

\footnotetext{
${ }^{11}$ Para ahondar en este tipo de violencia transfóbica en la Argentina es imprescindible la alusión al proyecto "El archivo de la memoria trans", impulsado por un colectivo audiovisual argentino que busca proteger, reconstruir y reivindicar la memoria trans argentina a través de fotos, vídeos y recortes de prensa y denunciar públicamente las desapariciones y asesinatos de mujeres transexuales y transgénero desde los años de la dictadura hasta el presente. Puede consultarse más sobre esto en el siguiente reportaje: http://revistaanfibia.com/ensayo/esta-se-fue-esta-murio-estaya-no-esta/

12 https://www.pagina12.com.ar/diario/suplementos/soy/1-3912-2015-03-27.html
} 
previamente cristalizado. Es por eso que tanto en la novela como en el relato "Sueño con medusas" aparecen numerosas bromas teñidas de humor negro acerca de la necesidad de crear organizaciones similares a HIJOS pero para otro tipo de parentesco como "SOBRINOS o NUERAS" (Los topos 18; 76 73), sobre "los neodesaparecidos o los postdesaparecidos" (Los topos 80), o incluso sobre los propios métodos de exterminio que usaron los militares ("Me preguntaba por qué los militares, para deshacerse de los cuerpos, no los quemaron a todos y listo: una buena forma de evitar que ahora la gente ande exhumando huesos", Los topos 88). En el relato "Sueño con medusas", se burla también del uso que hacen asociaciones como HIJOS del capital simbólico de los desaparecidos, que acaban literalmente estampados en las remeras como si de "estrellas del rock" se tratara. Ludo -la tercera pata del trío amoroso conformado por ella, Romina y el protagonista- se hace una remera con la foto de su tía desaparecida que "se parecía bastante a Cobain ... Y entonces, entre los que la veían por primera vez, estaban los que le preguntaban quién era y los que directamente le decían ah, vos sos fan de Nirvana" (76 73). También le hace otra a él con una foto de sus padres: "una especie de dúo Pimpinela un poco más hippie" (76 73). Este tono marcadamente sarcástico, negro y siniestro pretende desacralizar el imaginario de las víctimas que se había tendido a idealizar y mitificar y que "ya sea por operaciones de ocultamiento o de mistificación, corría el riesgo de quedar congelada en situación de improfanable" (Kamenszain 19). Bruzzone pretende evitar cualquier parámetro ético y estético impuesto por el discurso de la memoria en los textos que abordan el tema de la desaparición, de hecho, ha llegado a afirmar sobre su postura de no militancia que "como escritor no [le] interesa tomar partido" (Friera). Es decir, del mismo modo que el protagonista no acaba de sentirse cómodo con el discurso militante de HIJOS, Bruzzone decide posicionarse en una crítica apartidista que denuncie sin tapujos el impacto emocional e identitario que supuso el trauma de crecer siendo hijo de desaparecidos, pero al mismo tiempo se vale de la incorrección política y la parodia para advertir de los peligros que conlleva institucionalizar una única línea 
CATEDRAL TomAda: Revista de crítica literaria latinoamericana / Journal of Latin American Literary Criticism Desacralizando el espacio de lo narrable: (pos)memoria, autoficción y mercado editorial en Los topos y 76 de Félix Bruzzone

de lectura sobre el duelo, la pérdida y la memoria desde las propias organizaciones de familiares y víctimas de la dictadura.

En este sentido, me parece que Bruzzone concuerda con las críticas que Sarlo plasma en Tiempo pasado contra los discursos de la memoria (particularmente contra la canonización del testimonio) por haberse convertido en la única manera aceptable de narrar la violencia del pasado. Según Sarlo, el daño colateral que surge de esta coyuntura es la pérdida de potencial y de distancia crítica vinculada al giro subjetivo de la cultura de la memoria que parte de la premisa utópica de que es posible entender el pasado desde su lógica propia. En términos de Hirsch, su humor y su estilo paródico serían una forma de "posmemoria afiliativa", capaz de establecer vínculos afectivos más allá de la comunidad cultural de referencia (Sosa 77). Como ha señalado Beatriz Sarlo, “Los topos no podría haber sido escrita hace diez años. No porque Bruzzone tenía entonces poco más de veinte años..., sino porque debieron suceder algunos hechos para que el campo de lo 'escribible' sobre desaparecidos se ampliara para aceptar el cruce de géneros y la comicidad" (“Condición”). Por tanto, aunque el tono políticamente incorrecto y corrosivo, su continua transgresión genérica o su tratamiento estereotipado y frívolo de la identidad de género puedan invalidar el objetivo disruptivo e iconoclasta de su obra, hay que reconocerle a Bruzzone la valentía de arriesgar y ampliar los límites de lo narrable como propuesta para crear nuevas herramientas discursivas que ayuden a conciliar una sociedad democráticamente más madura.

\section{¿Escritura como resistencia o insistencia?}

Durante la transición democrática, surge en Argentina una desbordante cantidad de discursos sobre la memoria y los derechos humanos, que, si bien ha sido absolutamente decisiva en la normalización democrática del estado de derecho argentino, institucionalizó una forma "oficial” o "mejor" de recordar que, sin duda, ha relajado la necesidad de seguir buscando nuevas vías para seguir repensando y 
narrando el pasado y sus consecuencias en el presente. Aunque en las últimas décadas se haya producido un notable giro subjetivo, autobiográfico y afectivo de la mano del género testimonial, confesional, la autobiografía y otras narrativas del yo, que implica una vuelta a las representaciones realistas y personales, en mi opinión no habría que meter la autoficción (o al menos no todos los relatos que puedan encajar a priori en ese pacto de lectura) en el mismo cajón de la producción realista y burguesa del siglo XIX y gran parte del XX, ya que la matriz ideológica en la que nace la mayoría de los textos autoficcionales pretende romper justamente con esa correlación decimonónica entre discurso-verdad-autor. La narrativa de Bruzzone, con esa continua ruptura incómoda con la tradición en la que se inserta, con la línea que separa realidad y ficción, y con los pactos de lectura de los géneros populares, se convierte en un ejemplo paradigmático de esto. Al mismo tiempo, esta radicalidad le sirve como parapeto frente a los que intenten argumentar que la autoficción no es algo nuevo y que la generación anterior ya lo hacía y mezclan confesión con testimonio y autobiografía. En este sentido, Alberto Giordano distingue dos líneas de interpretación: por un lado, los que ven en ese giro autobiográfico una oportunidad para "poner el arte en contacto con la vida para que se fortalezcan y se acrecienten en cada uno las posibilidades de reinvención”, donde se inserta él; y, por otro:

los que se entusiasman con la hipótesis de que habríamos entrado en la era del fin de la autonomía del arte... [que] observan con interés la proliferación de escrituras autobiográficas porque ese fenómeno los confirma en la creencia de que el futuro (futuro paradójico de disolución) habría quedado en manos de un conjunto de prácticas textuales que minan los fundamentos imaginarios de la diferencia ficción/realidad.

Al polarizar el debate y recurrir al eje apocalípticos-integrados, ridiculiza la opción opuesta a la suya y no repara en el hecho de que Ludmer avisa de que no se pueden usar las mismas categorías críticas para estas narrativas postautónomas 
porque proponen una superación de esos ejes binarios. Aunque la autoficción tenga elementos en común con otras narrativas del yo, el lugar de enunciación y la intención inciden, intervienen y condicionan la interpretación del producto final. Por otro lado, Ilse Logie argumenta que el auge de la autoficción "no se emparenta con la redefinición de la intimidad que se ha dado en llamar 'extemidad, o sea, la autoexposición del yo, el impulso irrefrenable de exhibir la propia intimidad en el espacio público a través de los medios de comunicación o Internet” (87) como una fetichización pública de lo privado. Si bien estoy de acuerdo en parte con esto, coincido con Giordano en que la crítica no puede limitarse a intentar discernir y “distinguir los ejercicios autobiográficos que configuran auténticas experiencias artísticas de los que se reducen a la mera exhibición narcisista y la autocomplacencia". Es decir, aunque tampoco creo que el impulso narrativo desde el que surgen Los topos o 76 y su estilo autoficcional parta en un primer momento de la vanidad, el impudor o las ganas de autopromoción de Bruzzone sino de una necesidad existencial por poner a prueba la resistencia de las creencias, por encontrar respuestas a un trauma personal y poder superarlo verbalizándolo y exponiéndolo públicamente para comprobar sus flaquezas y fortalezas, no hay que pasar por alto que la cooptación que el mercado hace de las narrativas de la memoria en el Cono Sur y sus estrategias de promoción también intervienen en el proceso hermenéutico que condiciona tanto las elecciones narrativas que el autor toma como el sentido con el que se reciben los textos.

Por tanto, llegados a este punto, la pregunta de qué representa la escritura y la literatura para Bruzzone se hace obligatoria. Entiendo que esta respuesta es múltiple, aunque todas sus variantes forman parte de un todo interconectado. En primer lugar, la escritura para él tiene una dimensión performática que usa el capital público de su figura de autor para hacer pedagogía política ligada a un ejercicio de recuperación de la memoria colectiva y a la creación de un espacio abierto de debate sobre cómo construir hoy un estado democrático. Aunque él mismo es consciente de que la función social del autor en el siglo XXI ha mutado y se ha diversificado ("Los siete locos" 2:15-3:30), Bruzzone tiene una concepción de la literatura como 
herramienta crítica desde la que construir ciudadanía. Eso nos lleva a la segunda respuesta: la escritura como terapia psicoanalítica, como catarsis, como mecanismo de aprendizaje y superación del trauma personal haciéndolo público, exteriorizándolo. Es decir, su forma de representar el duelo es personal, pero aspira a abrir un nuevo camino para que otros puedan deshacerse de los corsés morales que imponen una única manera sectaria de procesar una experiencia tan compleja como el duelo. Por último, la literatura como resistencia ante una realidad desesperanzadora, como último recurso ante la incertidumbre suspendida en el tiempo, como una forma de crear respuestas alternativas ante la imposibilidad legal y real de cerrar ese limbo fantasmal que es la condición de desaparecidos.

Esta última faceta de la escritura se observa claramente en la carta de Bruzzone dirigida a sus padres que comentaba al inicio. Para el protagonista de Los topos o de otros relatos como "Otras fotos de mamá", la investigación y el proceso de obtención de pruebas se convierte en una obsesión porque tiene esperanzas de poder encontrar a alguien que lo cure del desarraigo que siente, alguien que le dé la última pieza con la que cerrar el rompecabezas. Tirando de ese difuso hilo autoficcional que une al autor con el narrador-protagonista, se puede inferir que para Bruzzone la escritura es una manera de arraigarse y agarrarse a la realidad y de lidiar con el complejo proceso en el que oscila por momentos entre el autoconvencimiento de que sus padres están muertos y la remota posibilidad de que estén vivos en algún sitio y que algún día aparezcan, ya que no ha podido tener confirmación fehaciente de sus muertes. De ahí que en la carta no sea capaz de hablarles en pasado, porque hasta que no encuentre sus cuerpos o sepa qué pasó seguirán siendo un asunto no resuelto. Se parapeta en la ironía y el humor para no quedar expuesto como iluso o ingenuo y poder seguir manteniendo una mínima puerta abierta: "Me animo a escribirles porque como no sé dónde están quizá todo lo que se dice de ustedes sea mentira y bueno, capaz que justo hoy leen Anfibia y se llevan una linda sorpresa. Hay que insistir". Quizá realmente no exista esa última pieza del rompecabezas, pero Bruzzone demuestra que al menos se puede tratar de escribir. 


\section{Bibliografía}

Alberca, Manuel. El pacto ambiguo. De la novela autobiográfica a la autoficción. Biblioteca Nueva, 2007.

Barthes, Rolland. S/Z. Siglo XXI, 2009.

Bruzzone, Félix. 76. Los topos. Random House Mondadori, 2008.

. Un clásico + dos nuevos cuentos. Momofuku, 2013 [Tamarisco, 2008].

. "Félix Bruzzone en Cuentomilibro.com". Youtube, 2009,

https://www.youtube.com/watch?v=nXvkDQYxNfA Accesed 20 Nov.

2018.

. "Félix Bruzzone en Los siete locos parte I". Youtube, 2010,

https://www.youtube.com/watch?v=yiuG9wRdZmo\&t=253s Accesed 20

Nov. 2018.

."Félix Bruzzone en Los siete locos parte II". Youtube, 2010,

https://www.youtube.com/watch?v=MojjEc15cf8 Accesed 20 Nov. 2018.

. "Paciencia de tenedores y cucharas". Revista Anfibia, 2016,

http://www.revistaanfibia.com/cronica/paciencia-de-tenedores-y-

cucharas/ Accesed 20 Nov. 2018.

Caamaño, Martín. “Entrevista a Félix Bruzzone”. Los Inrockuptibles, 2015,

https://losinrocks.com/entrevista-a-f\%C3\%A9lix-bruzzone-

a2e5d2c5259d Accesed 20 Nov. 2018.

Casas, Ana. "Memorias del desastre: la autoficción en la literatura de los hijos (y los nietos)”. Juan Manuel González Álvarez (ed.), La impronta autoficcional. (Re)fracciones del yo en la narrativa argentina contemporánea. Iberoamericana - Vervuert, 2018.

Drucaroff, Elsa. Los prisioneros de la torre. Política, relatos y jóvenes en la postdictadura. Emecé, 2011. 
Friera, Silvina. "Entrevista a Félix Bruzzone: 'Cómo rastrear el pasado con las letras"”. Página 12, http://www.pagina12.com.ar/diario/suplementos/espectaculos/4-112562008-09-12.html Accesed 20 Nov. 2018.

Gallego Cuiñas, Ana. "Comienzos de la novísima novela argentina (2001-2011)". Hispamérica, no. 130, 2015, pp. 3-14.

"Las narrativas del siglo XXI en el Cono Sur: estéticas alternativas, mediadores independientes". Ínsula, no. 859-860, 2018, pp. 8-12.

Gasparini, Philippe. “La autonarración”. Ana Casas (ed.), La autoficción. Reflexiones teóricas. Arco Libros, 2012.

Gatti, Gabriel. Identidades desaparecidas. Peleas por el sentido en los mundos de la desaparición forzada. Prometeo Libros, 2011.

Giordano, Alberto. "Cultura de la intimidad y giro autobiográfico". Pensamiento de los confines, no. 21, diciembre 2007, http://rayandolosconfines.com/pc21_giordano.html Accesed 20 Nov. 2018.

Gómez, Leticia. "El concepto de postmemoria en tres novelas argentinas recientes". Moderna Sprak, no. 1, 2014, pp. 38-44.

Hirsch, Marianne. Family frames: Photography, Narrative and Postmemory. Harvard University Press, 1997.

Ludmer, Josefina. Aqui América Latina. Eterna Cadencia, 2010. . "Literaturas postautónomas 2.0". Propuesta Educativa, no. 32, 2009, pp. 41-45.

Marling, William. Gatekeepers. The emergence of World Literature and the 1960s. Oxford University Press, 2016.

Sarlo, Beatriz. Tiempo pasado: cultura de la memoria y giro subjetivo: una discusión. Siglo XXI, 2005.

. "Condición de búsqueda. Sobre Los topos de Félix Bruzzone". Diario Perfil, 2008, 
CATEDRAL TomAdA: Revista de crítica literaria latinoamericana / Journal of Latin American Literary Criticism Desacralizando el espacio de lo narrable: (pos)memoria, autoficción y mercado editorial en Los topos y 76 de Félix Bruzzone

http://www.diarioperfil.com.ar/edimp/0319/articulo.php?art=114

52\&ed= 0319 Accesed 20 Nov. 2018.

Thompson, John. Merchants of Culture. The Publishing Business in the TwentyFirst Century. Plume, 2012.

Young, James E. At Memory's Edge: After-Images of the Holocaust in

Contemporary Art and Architecture. Yale UP, 2002.

Vanoli, Hernán. "Sobre editoriales y la configuración de una cultura". Nueva sociedad, $\mathrm{N}^{\mathrm{o}} 230,2010$, pp. 129-151. 